\title{
EKSISTENSI DAN AKTUALISASI DIRI MANUSIA SEBAGAI IDE PENCIPTAAN SENI LUKIS
}

\author{
Wisnu Aji Kumara \\ Program Studi Magister Penciptaan dan Pengkajian Seni \\ Program Pascasarjana Institut Seni Indonesia, Yogyakarta, Indonesia \\ e-mail : wisnuartproject@gmailcom \\ Diterima : 15 Juni 2019. Disetujui : 10 September 2019. Dipublikasikan : 27 Desember 2019 \\ CC) (7) $\begin{aligned} & \text { (C) } 2019 \text { - DESKOVI Universitas Maarif Hasyim Latif. Ini adalah artikel dengan akses } \\ & \text { terbuka di bawah lisensi CC BY } 4.0 \text { (https://creativecommons.org/licenses/by/4.0/) }\end{aligned}$
}

\begin{abstract}
ABSTRAK
Penulisan tugas akhir karya seni ini bertujuan untuk mendeskripsikan tema, teknik visualisasi dan bentuk lukisan yang berjudul Wayang Beber sebagai inspirasi penciptaan lukisan bertema cerita rakyat Jawa.Metode yang digunakan dalam penulisan dan penciptaan karya seni lukis ini adalah observasi langsung di Pacitan dan studi langsung ke seniman wayang beber, improvisasi dengan cara membuat sketsa-sketsa dari figur-figur/tokoh wayang serta ornament pada background dan visualisasi dengan cara menerapkan teknik sungging pada penciptaan lukisan wayang beber cerita rakyat jawa. Visualisasi lukisan wayang beber ini menggunakan teknik sungging, media cat akrilik pada kanvas. Proses penciptaan karya seni lukis tersebut menghasilkan 9 buah bentuk lukisan dekoratif ilustratif yang berisi cerita rakyat jawa dengan figur-figur sesuai dengan narasi, dengan berbagai ukuran yang berbeda yaitu: Timun Mas, Lutung Kasarung, Kembang Wijaya Kusuma, Aji Saka, Jaka Tarub, Cindelaras, Srikandi Meguru Manah, Kayon dan ShangyangIsmaya.
\end{abstract}

Kata kunci: Wayang Beber, Inspirasi, Penciptaan, Cerita Rakyat Jawa.

\begin{abstract}
This final project was aimed for describing the theme, visualization technique and paintings whose the title was Wayang Beber As An Inspiration In Creating Javanese Folklore-Themed Paintings.The methods employed in writing this final project and in creating the artwork, in this case was wayang Beber as a Javanese folklore paintings, were observation conducted in Pacitan and direct study from the artist of Wayang Beber, improvisation through sketching the characters of the wayang and creating ornament and visualization on the background by applying sungging technique. In visualizing the wayang beber paintings, the painter employed sungging technique, an acrylic medium on canvas. After going through a set of processes, the painter was able to create 9 differentsized decorative-illustrative paintings told about Javanese folklore in which the characters corresponded to the story, including Timun Mas), Lutung Kasarung, Kembang Wijaya Kusuma, Aji Saka, Jaka Tarub, Cindelaras, Srikandi Meguru Manah, Kayon and Shangyang Ismaya
\end{abstract}

Keyword: Wayang Beber, Inspiration, Creating, Javanese folklore.

\section{PENDAHULUAN}

\section{Manusia dan eksistensinya}

Pengambilan peran serang individu dimuka bumi ini menjadi hal yang penting, dimana setiap seseorang mempunyai peran-perannya masin-masing dalam kehidupan.Kemampuan manusia sebagai seorang individu yang utuh membuat diri mereka memiliki kecenderungan mengaktualisasikan diri mereka dalam pergaulan sosial. Sejalan dengan itu, Kierkegaard dalam M. Dagun (1990 : 50) mengatakan bahwa :

"eksistensi hanya dapat diterapkan kepada manusia sebagai individu yang kongkrit, karena hanya aku individu yang kongkrit ini yang bereksistensi, yang sungguh-sungguh ada dan hadir dalam realitas yang sesungguhnya oleh karena itu, aku yang kongkrit ini tidak dapat direduksi kepadarealitas-realitas lain, sebab jika aku yang kongkrit ini direduksi kepada realitasrealitas lain, maka realitas diriku yang sesungguhnya sebagai individu yang bereksistensi tercampur dengan realitas-realitas itu. Dengan demikian, aku individu yang kongkrit ini tidak memiliki kebebasan untuk mengembangkan dan mewujudkan diriku sebagaimana adanya karean aku tergantung pada realitas-reallitas itu membuat aku tidak bisa merealisasikan diriku sebagaimana aku kehendaki."

\section{Dualitas pemberian Tuhan}


Setiap yang diberikan Tuhan mempunyai sebah konsekwensi penting, tak dapat dipungkiri setiap apa yang ia ciptakan selalu berpasangan. Seperti kita lihat bagaimana ia menciptakan siang dan malam, hidup dan mati, laki-laki dan perempuan da begitu seterusnya, semua menjadi berarti karena setiap penciptaanNya mempunyai komparasi. Ini tidak lain mempunyai tujuan yang sadar maupun tidak manusia sebagai makhluk berakal pastinya dapat mengambil manfaat daripanya.

Dalam berkarya seni, orisinalitas merupakan hal yang sangat penting. Dalam setiap penciptaan karya seni, orisinalitas selalu dituntut sebagai sebuah bentuk pertanggungjawaban seniman atas karya yang ia ciptakan. Pada kasus penciptaan karya seni saat ini, orisinalitas bukan hanya semata sebagai sebuah bentuk pertanggung jawaban seniman, namun orisinalitas dipandang sebagai nilai kebaruan yang ditawarkan seniman dalam karya seninya baik dari segi konteks maupun konten, yang dapat dilihat sebagai pembanding antara si seniman yang satu dengan yang lain.

Berdasarkan uraian singkat diatas, maka dapat ditarik rumusan masalah penciptan seni lukis dengan judul eksistensi dan aktualisasi diri manusia sebagai berikut :

1. Bagaimana memilih idiom bentuk yang tepat guna memvisualkan karakter individu dalam penciptaan seni lukis berjudul eksistensi dan aktualisasi diri manusia ?

2. Bagaimana merepresentasikan eksistensi dan aktualisasi diri manusia menjadi ungkapan yang metaforik melalui karya seni lukis ?

\section{Orisinalitas}

Pada era kontemporer saat ini, bahkan dapat dikatakan sangat tidak mungkin menemukan sesuatu yang baru dalam proses penciptaan karya seni, karena semuanya sudah dibuat, semua saling terpengarung dam mempengaruhi. Begitupun dengan apa yang terjadi pada dunia seni lukis, apa yang kita temukan sekarang hanyalah semata-mata hasil rekonstruksi dan keterpengaruhan daripada seni-seni yang telah diciptakan dahulu. Apa yang kita jumpai sekarang adalah penyempurnaan, melengkapi serta memberikan makna baru dari hasil cipta karya seni yang telah diciptakan atas periode seni yang hadir sebelumsebelumnya.

Maka demikian pengaruh dari pelukis-pelukis baik dari segi gaya maupun teknik dalam berkarya seni adalah sesuatu yang sangat lumrah dan wajar adanya. Namun walaupun demikian, seniman dituntut untuk dapat menampilkan perbedaan-perbedaan mendasar pada karya seni yang ia ciptakan baik itu dari segi tema, konsep, bentuk, serta teknik yang ia gunakan, sehingga bentuk visual yang muncul adalah sebuah keorisinalitasan dari proses kreatif sang yang dilalui sang seniman. Hal ini bertujuan tidak lain untuk menghindari kesan menjiplak daripada karya seni seniman yang menjadi acuannya dalam berkarya.
Dalam penciptaan seni lukis, juga tidak dapat dipungkiri bahwa penggunaan dekonstruksi bentuk serta stilisasi sudah sangat sering kali dilakukan. Hal ini bertujuan tak lain guna menemukan idiom bentuk ataupun bentuk-bentuk estetik, yang dirasa tepat serta dapat mewakili dari ide penciptaan sang seniman,sebagai sarana/ mediapenyampaian ide yang ia pendam ke dalam bentuk visual yang akan dibaca oleh banyak orang. Penggunaan-penggunaan dekonstruksi bentuk dengan tujuan semacam ini teramat kuat dalam segi bentuk dan teramat sering kita jumpai pada karya-karya bergaya kubisme.

Dengan demikian, penciptaan seni lukis ini akan mengacu pada bentuk-bentuk yang dekonstruktif, guna mendapatkan kecenderungan bentuk yang kuat dengan menitik beratkan pada konsep kubisme analitis, yang melihat sebuah objek dengan mengawali penciptaannya dari analisa bentuk yang kemudian memecahnya menjadi beberapa faset lalu melukiskannya secara bersamaan. Ini dirasa selaras dengan konsep penciptaan yang diakukan dengan bebrapa pengembangan dalam proses analisanya. Objek dianalisa dari berbagai sudut pandang dengan fokuseksisitensi manusia sebagai tolok ukurnya.

Salah satu seniman yang berpengaruh kuat bagi penulis yakni Picasso dengan gaya kubismenya yang sangat kuat. Tak dapat dinyana, Picasso sebagai seorang yang diakui sebagai penemu kubisme menjadi salah seorang tokoh terpenting dalam perjalanan seni rupa modern.Kekuatan bentuk yang diciptkan Picasso melalui garis-garis yang tegas terasa sangat kuat mewakili karakternya.

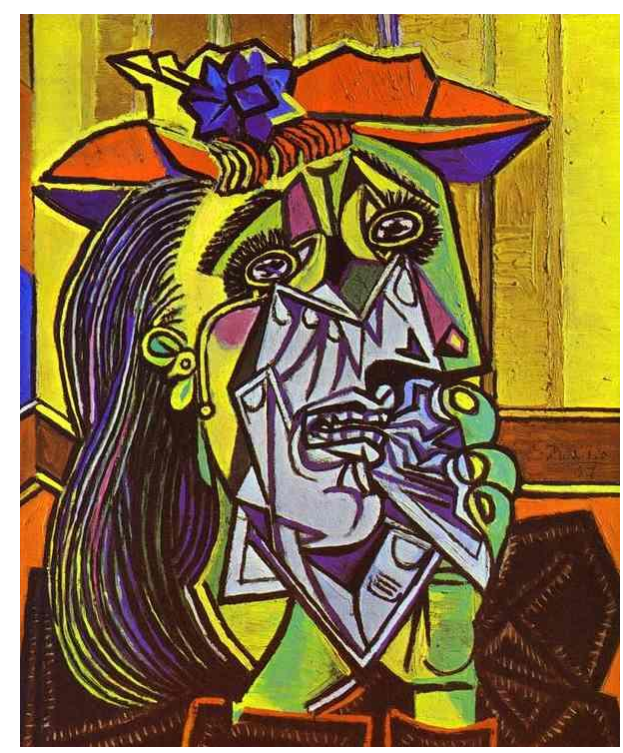

Gambar 1 : Pablo Picasso, The Weeping Woman Oil on canvas, 1937

(Sumber :https://www.pablopicasso.org/the-weepingwoman.jsp\#prettyPhoto)

Pada gambar karya Picasso The Weeping women di atas, terlihat dekonstruksi bentuk yang sangat dramatis dari pembentukan objek wanita yang 
diinterpretasikan sedang menagis sesuai dengan judulnya, dengan tangan kanan berada pada pipi kanan dan tangan kiri sedang memgang tisu dengan objek mata yang dibuat terlihat sendu. Penggunaan warna primer dengan tone yang sedikit diredupkan mngesankan kesan kelam. Terlihat dekonstruksi bentuk yang sangat kuat pada bagian wajahnya dengan garis yang kuat dan tajam, serta penggunaan blok-blok warna pada bagian tertentu.

Seniman lain yang menjadi rujukan penting saya ialah George Condo. Pelukis kelahiran Concord, New Hampsire, Amerika (1957) ini menyelesaikan pendidikannya di University of Massachusetts Lowell dengan focus studi tentang sejarah seni dan teori musik. Pertemuannya dangan pelukis modern ternama Jean Michel Basquiat saat bergabung dengan sebuah band yang bernama The Girl yang didalamnya juga pelukis abstrak Mark Dagley. Pertemua itu membuat George Condo memilih pindah ke New York sebagai seorang seniman, yang kemudian ia menggelar pameran tunggal perdananya di East Village Galeries antara 1981 dan 1983 sembari ia bekerja pada studio milik Andy Warhol.

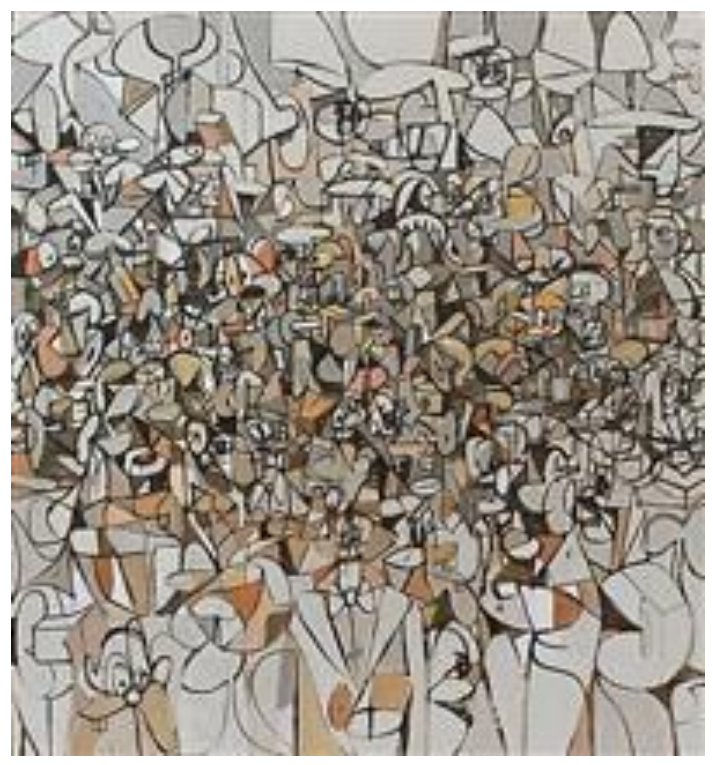

Gambar 2 : George Condo

Population of Forms, 2011

(Sumber :http://www.artnet.com/artists/georgecondo/2)

Pada gambar karya George Condo diatas terlihat komposisi yang padat dari garis-garis yang saing bertautan satu dengan lainnya, yang membuat sekan-akan keseluruhan bentuk dari karya ini memnuhi bidang dua dimensional tersebut.Namun dia masih menisakan ruang untu menyeimbangkan komposisinya dengan menggunakan bentuk-bentuk garis yang memiliki ruang yang lebih besar tidak sepadat garisgaris yang berada di tengah.Penggubahan bentuk yang kuat terjadi pada objek-objek yang digambarkan yang dapat diinterpretasikan sebagai bagian tubuh dan kepala-kepala yang saling berhimpitan memenuhi ruang bagian tengah kanvas.

Dengan demikian pengaruh antara Picasso dan George Condo tak dapat dipungkiri juga sangat terasa dalam proses kreatif saya, namun ini tak serta merta membuat saya menajdi slah satu dari pelukis inspirasi saya. Tentunya saya mencari cirri khas yang dapat menjadi pemda antara karya saya dengan karya yang seniaman yang menjadi acuan (inspirasi).Yang menjadi point penting pembeda antara karya saya dengan karya Picasso dan George Condo terletak pada garis yang tajam dan dekonstruksi bentuk yang saya buat dengan sapuan kuas yang halus.Tentunya pula dengan mengangkat tema yang berbeda dari dua seniman tersebut.

\section{Kubisme Sebagai Pilihan bentuk}

Pemilihan seni lukis sebagai media berkarya dirasa saya sebagai media yang cukup relevan saat ini, dikarenakan distribusinya yang mudah dan cepat serta keefektifannya sebagai media kritik dan kritis terhadap fenomena yang terjadi.Pemilihan idiom bentuk yang tepat saya rasa sangat penting dilakukan untuk menagkap fenomena dan problematika yang terjadi dari sebuah eksistensi manusia tersebut ke dalam lukisan.

Kubisme merupakan salah satu aliran terpenting dalam seni rupa, dimana ia muncul sebagai salah satu bentuk wujud dari teori dekonstruksi yang lahir pada abad ke 20. Ini merupakan kelanjutan dari pemikiran Cazzane pada tahun 1907 yang menganggap bahwa setiap setiap objek ialah bentuk-bentuk geometris abstrak. . Pelopor gaya kubisme ini tak lain ialah Pablo Picasso (1811973) dan Georges Braque (1882-1963)



Gambar 3 : contoh lukisan beraliran kubisme Pablo Picasso: "Guernica"

3,5 m x 7,8 m, cat minyak pada kanvas, 1973 Sumber :https://www.pablopicasso.org/guernica.jsp

Dalam perkembangannya, kubisme melalui dua masa penting yakni masa analitis, dan masa sintesis.Masa analitis terlihat pada tahun 1909 - 19012 saat kubisme mengembangkan teori yang dikatakan oleh Soedarso Sp. (2000: 144) sebagai toeri yang benarbenar kubistik yakni teori simultanitas. Teori ini dalam penerapannya diawali dengan analisa objek yang kemudian dipecah-pecah menjadi beberapa faset yang dianalisa dari berbagai macam sudut pandang yang kemudian dilukiskan secara sekaligus.Yang kedua 
yakni masa sintesis.Bertolak belakang dari masa sebelumnya, pada masa sintesis ini seakan-akan lukisan disusun dari berbagai macam bidang warna yang transparansi dan saling tumpang menumpang sehingga solah membentuk objek yang dilukiskan.

Dilain sisi kubisme memberi ruang yang sangat memungkinkan setiap seniman untuk mengembangkan gaya-gaya baru berdasarkan pada prinsip-prinsip yang ada pada gaya kubisme itu sendiri. Seperti apa yang dilakukan oleh Fernand Leger dengan bentuk kubistik kuat dengan warna-warna yang sangat cemerlang ataupun pelukis terkenal seperti Robert Dlaunay.

Penangkapan objek pada satu waktu yang kemudian disublimasi kedalam lukisan membuat kubisme terasa cukup dekat sebagai sebuah gaya dalam seni luki yang dapat mengcounter kebutuhan penciptaan seni yang berpaku pada 2 waktu, yakni masa lalu dan saat ini. kubisme analitis penulis pandang sebagai sebuah konsep yang menarik dimana kejadian dari penafsiran akan teks masa lalu dirkam kemudian dibenturkan untuk dipadupadankan kembali kedalam sebuah bentuk.

Seorang seniman dituntut untuk menempatkan dirinya secara benar.Tentunya keberpihakan seniman ini tergantung daripada standing poision si seniman melihat fenomena yang terjadi, baik dari internal (dari dalam dirinya) maupun dari eksternal (halyang dari luar dirinya).Sudah barang pasti mayoritas seniman memilih menempatkan dirinya lebih condong ke "bawah daripada ke "atas.

Namun demikian, hal diatas sangatlah penting untuk melihat kecenderungan karya yang akan muncul nantinya dengan melihat darimana sudut pandang seniman merespon fenomena yang ada disekitarnya.

Dalam konsep penciptaannya, saya melatar belakangi penciptaan karya seni ini sebagai media kritik dan kritis guna sebagai alat bantu penyadaran yang bersifat estetik melihat feenomena eksistensi manuisa itu sendiri.

Dalam memvisualisasikannya, saya menggunakan banyak dekonstruksi bentuk seperti yang terjadi pada kubisme.Dengan grastruk yang kuat dan warna-warna akromatik sehingga memberi suasana kelam.Pencapaian volume bentuk pada beberapa karya dicapai dengan teknik chiaroscuro atau pencapaian gelap terang.Secara teknis ini diharapkan dapat memberikan kesan miris bagi apresiator.

\section{Seni Lukis}

Seni lukis dapat dikatakan bahwa unkgapan ide, perasaan dan imajinasi peupa yang bersifat subjektif dalam penciptaan bentuk-bentuk yang indah serta bermakna, dengan memanfaatkan elemen-elemen seni sertamempertimbangkan prinsip-prinsip dasar seni dalam penciptaan seni lukis.

Menurut Mikke Susanto (2011: 241), menjeaskan bahwa seni lukis adalah bahasa dari pengalaman artistic maupun ideologis yang menggunakan warna dan garis, guna mengungkapkan perasaan, mengekspresikan emosi, gerak, ilusi maupun ilustrasi dari kondisi subjektif seseorang. Seni lukis dapat dikatakan sebagai suatu ungkapan pengalaman estetik seseorang yang dituangkan dalam bidang dua dimensi (dwi matra), dengan menggunakan medium rupa, garis, warna, tekstur, shape, dan sebagainya (Dharsono, 2004:36)

\section{METODE PENCIPTAAN}

\section{Metode}

Setiap penciptaan seni apapun bentuknya tentunya melalui beberapa tahapan prosesuntuk menuju karya yang final. Tentunya hal tersebut tak lepas bermula dari dorongan yang memicu sang seniman untuk bergerak membuat suatu karya seni, baik dorongan dari dalam dirinya maupun dari luar dirinya sebagai sang seniman. Kemudian dilanjutkan dengan tahap bagaimana mewujudkan dorongan tersebut.

Dalam penciptaan ini, saya mengacu pada metode yang diterapkan Alma Hawkins dalam bukunya yang berjudul Creating Trought Dance yang diterjemahkan oleh RM. Soedarsono, yaitu" pertama eksplration (eksplorasi); kedua improvisation (improvisasi); ketiga form (pembentukan). Metode tersebut diatas merupakan metode yang sering diterapkan dalam penciptaan karya seni tari namun juga dapat kita adopsi kedalam penciptaan seni rupa (Soedarsono 2001:207)

Pada metode penciptaan yang telah disebutkan diatas, saya menerapkannya sebagai berikut :

1. Eksplorasi (ekploration), tahap ini adalah tahap awal dimana seorang seniman memulai langkahnya dalam melakukan penciptaan karya seni dengan melakukan berbagai macam penelusuran guna mendapatkan tema yang utuh guna dijadikan sebagai sumber penciptaan. Paada tahap ini termasuk didalamnya yakni berminajinasi, berfikir, merasakan serta merespon objek yang dijadikan sumber penciptaan. Dikarenakan pada tahap eksplorasi ini adalah dasar/ batu pijakan dalam berkarya seni, maka pada tahap ini diperlukan pencarian yang seluasluasnya daripada sumber refrensi serta informasi guna menentukan tema serta rumusan masalah penciptaan, baik berupa wawancara, membaca buku, menonton video dsb. Begitu juga dengan melakukan ekplorasi acuan visual dengan mencari serta melihat seniman-seniman lain yang mengangkat tema sejenis dengan penulis ataupun yang karyanya serupa dengan apa yang ada dalam bayang-bayang penulis, baik melalui menonton pameran, melihat katalog, maupun browsing diinternet.

2. Improvisasi (improvisation), pada tahap ini memungkinkan saya untuk melakukan berbagai macam percobaan (eksperiment) baik dari segi penggunaan material maupun mencoba menemukan bentu-bentuk artistik.

3. Forming (pembentukan), tahap ini pada metode penciptaan seni lainnnya juga biasadisebut 
dengan tahap eksecution (tahap eksekusi) .yakni pada tahap ini seniman mulai mewujudkan ide penciptaannya kedalam wujud yang nyata

\section{Bahan dan Alat.}

Bahan-bahan yang saya gunakan dalam proses visual pada penciptaan karya seni ini antara lain : cat, kanvas, kuas, kain lap serta ember wadah air guna mencuci kuas, palet, charcoal stik serta soft pastel. Proses visualisasi dilakukan dengan mengacu pada metode yang yang telah dijelaskan sebelumnya. Proses visualisasi diawali dengan pembuatan sketsa pada kertas (rancangan ide penciptaan) - memindahkan objek pada kanvas - pewarnaan - serta terakhir fininshing.

\section{PEMBAHASAN}

Dari proses kreatif yang saya lalui dalam penciptaan ini membuahkan 6 buah lukisan dengan dengan spesifikasi sebagai beriut :

\section{Menjinakkan Nafsu}

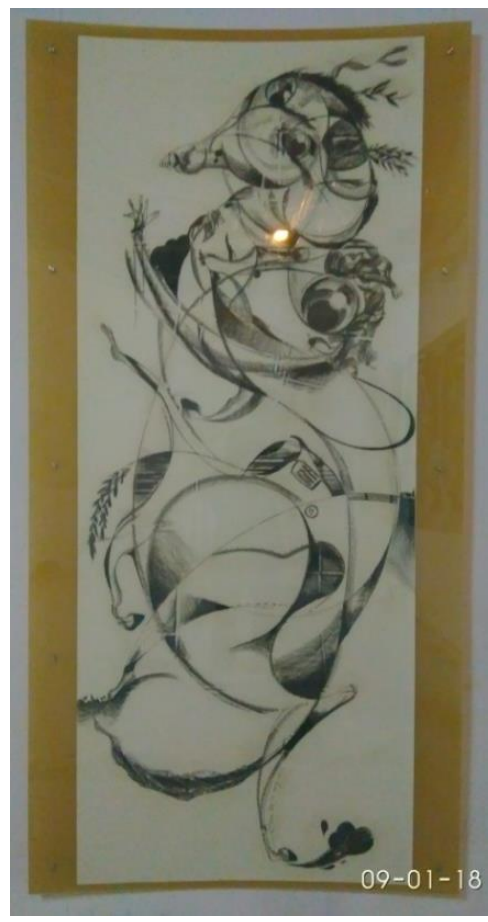

Gambar 4 :Menjinakkan Nafsu

$96 \mathrm{~cm}$ x $150 \mathrm{~cm}$, Pensil arang pada kertas, 2017

Pada gambar diatas terlihat sesosok laki-laki sedang menunggangi seekor binatang yang dapat diidentifikasi sebagai seeokor kuda.Idiom kuda dipilih sebagai simbol atas hawa nafsu yang ada pada diri manusia, yang secara tidak sadar dapat mengaburkan nilai eksistensial mereka, dimana hawa nafsu tersebut selalu mengekang yang kemudian secara sadar harus dapat dijinakkan.

\section{Badut}

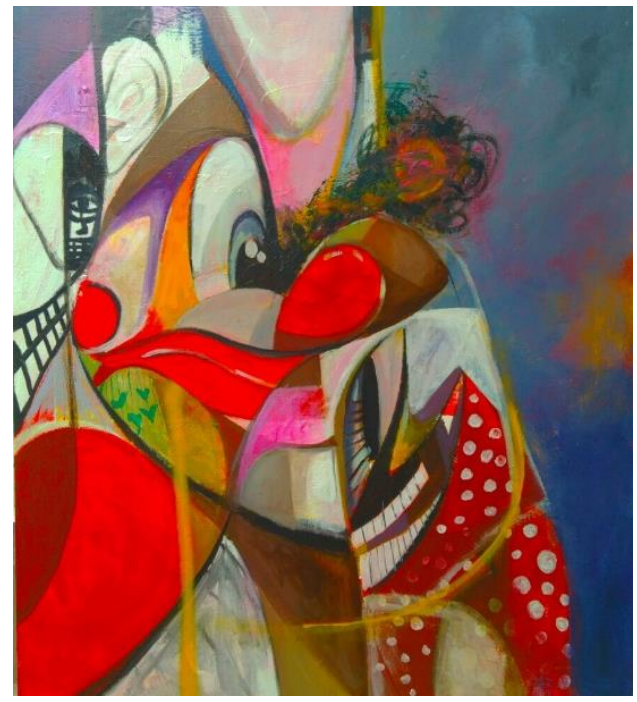

Gambar 5 :Badut

$165 \mathrm{~cm}$ x $175 \mathrm{~cm}$, akrylik pada kanvas, 2017

Pada gambar karya yang berjudul badut diatas menampilkan sosok yang dapat diidentiikasi sebagai seorang badut.Ini nampak jelas terlihat daripada bentuk mata serta hidung merah yang khas. Pada karya ini saya ingin mempelihatkan bagaimana seorang manusia mencoba segala berbagai macam cara guna tetap dalam eksisitensialismenya walaupun harus membohongi diri sendii dengan berperan sebagai orang lain dalam hidupnya.

\section{Melihat ke Dalam}

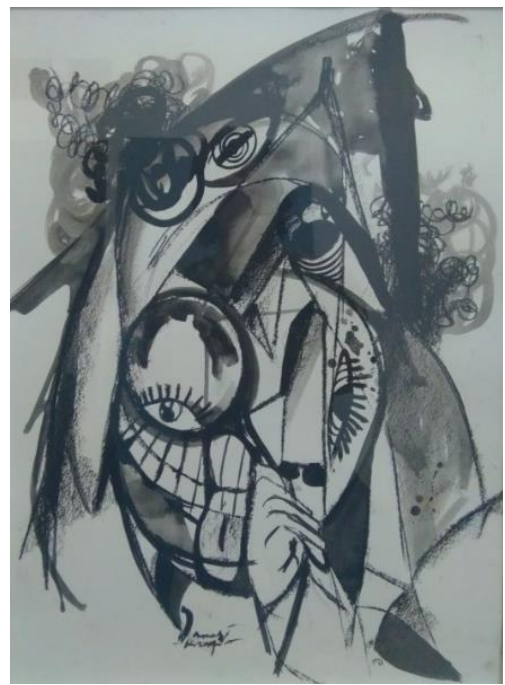

Gambar 6 :Melihat ke Dalam

$42 \mathrm{~cm}$ x $52 \mathrm{~cm}$, pensil arang dan tinta cina pada kertas, 2017

Pada gambar kaya yang berjudul melihat ke dalam diatas, menampilkan sosok manusia dengan 
mata yang terlihat besar, dengan tangan yang sedang memegang kaca pembesar. Kaca pembesar dipilih sebagai salah satu benda yang hadir dalam karya ini dikarenakan fungsinya yakni untuk melihat sesuatu yang berukuran kecil, yang sulit dilihat dengan batas kemampuan indra pengelihatan manusia. Kaca pembesar dalam hal ini saya asumsikan sebagai suatu alat yang dapat manusia gunakan untuk melihat jauh ke dalam dirinya, yang seyogyanya dapat mempertanyakan ulang makna dari eksistensi bagi dirinya.

\section{Bimbang}

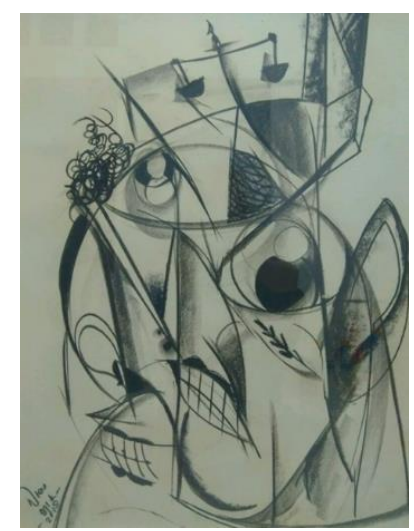

Gambar 7 :Bimbang

$52 \mathrm{~cm}$ x $65 \mathrm{~cm}$, pensil arang pada kertas, 2017

Manusia dihadapkan dengan berbagai macam problematika, terlebih lagi saat sia sedang mempertahankan eksisitensi dirinya sebagai manusia. Sebeggitu pentingnya sebuah eksistensi bagi dirinya kadnag kala mebmbaut ia berpikir keras untuk tetap "ada" dan terlihat bagi orang lain.

\section{Madness}

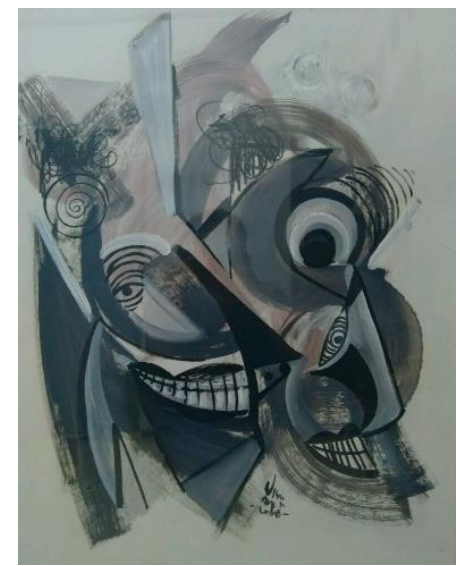

Gambar 8 :Madness

$60 \mathrm{~cm} \times 80 \mathrm{~cm}$, akrylik, pensil arang dan tinta cina pada kertas, 2018

Setiap sebuah cara dilkakuan dalam menjadikan dirinnya tetap eksis, manusia kadang kala dalam kebingungannya seringkali memunculkan "kegilaan-kegilaan" yang senantiasa ia coba untuk membuat diri mereka tetap "ada", selalu aktual, tak ingin tertandingi bahkan tak ingin tergantikan dengan orang lain.

\section{Kambing Hitam di Kepalamu}

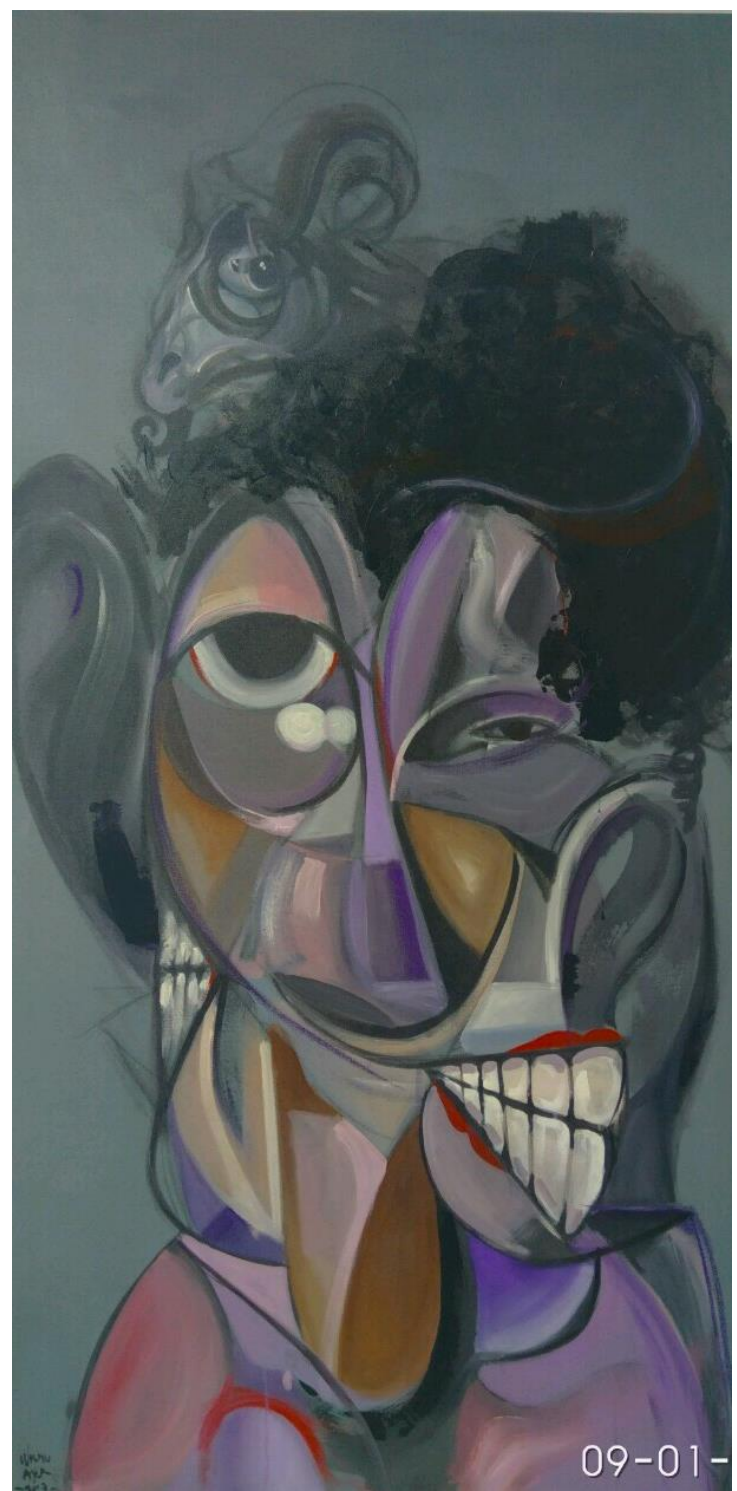

Gambar 9 :Kambing Hitam di Kepalamu $100 \mathrm{~cm}$ x $200 \mathrm{~cm}$ akrylik pada kanvas, 2017

Pada gambar karya yang berjudul kabing hitam dikepalamu ini, saya ingin melihat sebuah gejala sikologis manuisia dari suatu sudut pandang, yang dimana gejala tersebut seringkali baik sadar maupun tidak terjadi pada setiap diri manusia.Sifat ke"akuan" manusia dengan egosentris yang tinggi seringkali menafikan pandangan hati.Ketika sebuah kesalahan dilakukan, selalu muncul sikap-sikap pembennaran atas diri, dan seringkali manusia karena sifat tersebut mencari "kambing hitam" bagi dirinya. Bahkan 
7. Versus

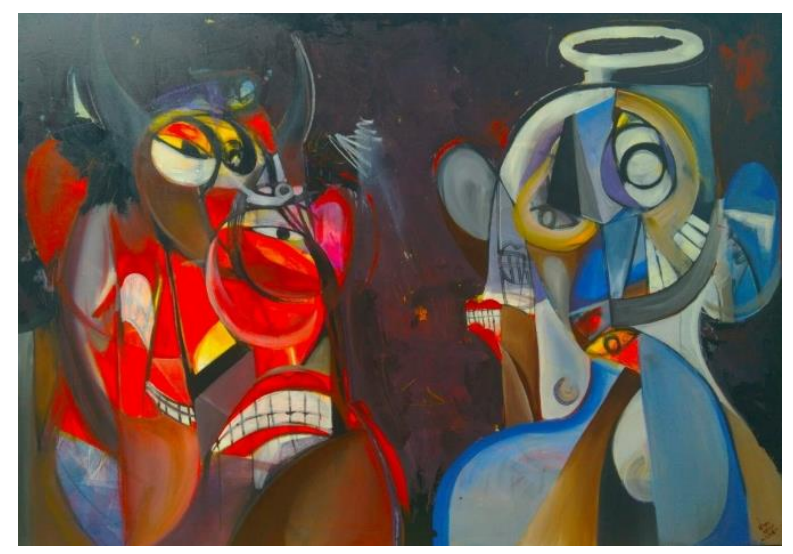

Gambar 10 :Versus

$150 \mathrm{~cm}$ x $200 \mathrm{~cm}$, akrylik pada kanvas, 2018

Dalam karya yang berjdul Versus ini, penulis menceritakan bagaimana sebuha pergolakan terjadi dalam diri manusia,antara apa yang baik dan buruk, antara yang patut dan yang tidak, antara hitam dan putih, dan semuanya itu merupakan sebuah dualitas yang mau tak mau selalu ada dalam kehidupan manusia.

Sering kali dualitas ini menjadi sesuatu titik yang sangat krusial bagi seseorang, dimana pergolakan-pergolakan yang akan mewujudkan dirinya sebagai seorang individu yang eksist bertemu yang kemudian akan memunculkan tindakan-tindakan.

\section{DAFTAR PUSTAKA}

Save M. Dagun,. 1990. Filsafat Eksistensialisme. Jakarta: Reineka Cipta

Sony Kartika, Dharsono. 2004. Seni Rupa Modern. Bandung: Rekayasa Sains.

Susanto, Mikke.2011. Diksi Rupa, kumpulan dan istilah seni rupa. Yogyakarta : DictiArt Lab \& Djagad Art House.

Soedarso Sp.2000. Sejarah Seni Rupa Modern. Yogyakarta: Studio Delapan Puluh Interprise berkerja sama dengan Badan penerbit ISI Yogyakarta

Soedarsono R.M .2001. Penelitian Seni Pertunjukan dan Seni Rupa.Bandung: MSPI (Masyarakat Seni Pertunjukan Indonesia) 
Wisnu Aji Kumara / DESKOVI : Art and Design Journal, Vol. 2, No.2, Desember 2019, 81-88

( Halaman ini sengaja dikosongkan ) 